\title{
Microstructures and Mechanical Properties of Hot Isostatic Pressed Parts of Ti-6Al-4VELI Alloy Spherical Powders with Three Different Diameter Distributions
}

\author{
Zeng Guang ${ }^{1,3}$, Mao Xiaonan', Zhao Yongqing1, Huang Chaowen ${ }^{1}$, Liang Shujin ${ }^{2}$, \\ Han Zhiyu ${ }^{2}$, Yan Fei ${ }^{2}$, Zhang Pingxiang ${ }^{1,2}$ \\ ${ }^{1}$ Northwest Institute for Nonferrous Metal Research, Xi'an 710016, China; ${ }^{2}$ Sino-Euro Material Technologies Co., Xi'an 710018, China; \\ ${ }^{3}$ School of Aerospace, Mechanical and Manufacturing, Royal Melbourne Institute of Technology, Melbourne, VIC 3001, Australia
}

\begin{abstract}
We report the microstructure and mechanical properties of Ti-6Al-4VELI (extra low interstitial) alloy parts fabricated with three diameter distributions of Ti-6Al-4VELI spherical powders by hot isostatic pressing (HIP), which were manufactured via plasma rotating electrode processing (PREP). The powders were canned and pressed at temperatures $940^{\circ} \mathrm{C}$ and pressure $120 \mathrm{MPa}$. $\alpha+\beta$ mixed phases in the specimens were observed through Optical Microscope (OM), Scanning Electron Microscopy (SEM) and energy dispersive spectroscopy (EDS) methods. The results show the microstructures of specimens are found to be strongly dependent on the different distributions of powders. The samples formed from fine powders $(45 \sim 100 \mu \mathrm{m})$ shows better microstructure properties than those formed from medium powders $(100 \sim 150 \mu \mathrm{m})$ and coarse powders $(150 \sim 250 \mu \mathrm{m})$. In addition, the billets formed from fine powders exhibit higher tensile strength and ductility than those formed via medium powders and coarse powders. These results are attributed to the initial microstructures of HIP samples, as confirmed by evaluating their fracture features.
\end{abstract}

Key words: TC4ELI alloy spherical powders; HIP; diameter distributions; microstructure, mechanical property

Ti-6Al-4V alloys have led to their use in large areas in aerospace, ships and warships, bio-medical and leisure applications ${ }^{[1,2]}$ with regard to their high capability in high strength to density ratio, favorable fatigue properties, outstanding fracture toughness and preferable corrosion resistance $^{[3,4]}$. Most complex structure parts of Ti-6Al-4V alloys are manufactured through casting resulting from their higher properties in casting and welding, which are able to be used under high strength ${ }^{[5-7]}$. However, casting Ti-6Al-4V alloys tend to influence the combination properties of casting parts directly according to their defects in shrinkage porosity, contraction cavities and air hole ${ }^{[8-10]}$. To overcome these unbeneficial approaches, near-net shaping (NNS) technology, in particular, hot isostatic pressing could help to shutting defects of casting parts thereby to heighten their density and mechanical properties ${ }^{[11,2]}$. In addition, hot isostatic pressing can produce large parts with improved mechanical properties and complex shapes comparing to several NNS methods including powder injection molding (PIM), cold isostatic pressing (CIP) or sintering ${ }^{[13,14]}$.

There have been a number of detailed studies of the processing and characterization of HIP Ti-6Al-4V and its alloys. Youngmoo Kim ${ }^{[15]}$ evaluated the microstructure and the mechanical properties of fully equiaxed or lamellar structure observed depending on the processing of parts formed via HIP over the intermediate temperature from $300{ }^{\circ} \mathrm{C}$ to $500{ }^{\circ} \mathrm{C}$. Furthermore, his group also reported the microstructural analysis and mechanical characterization of Ti-6Al-4V alloy parts fabricated using hot isostatic pressing (HIP) with prealloyed powders which were manufactured via gas

Received date: November 14, 2016

Foundation item: National Natural Science Foundation of China (51471044, 51671044); Dalian Youth Science and Technology Star Project Support Program (2016RQ005)

Corresponding author: Zeng Guang, Master, Senior Engineer, Titanium Alloy Research Center, Northwest Institute for Nonferrous Metal Research, Xi'an 710016, P. R. China, Tel: 0086-29-86231095, E-mail: guangbright@126.com

Copyright $($ C 2017, Northwest Institute for Nonferrous Metal Research. Published by Elsevier BV. All rights reserved. 
atomization, plasma atomization and the hydride/dehydride processes ${ }^{[16]}$ at temperatures in the range of $880 \sim 980^{\circ} \mathrm{C}^{[15]}$. However, relatively little attention has been paid to the observation on microstructure and mechanical properties of Ti-6Al-4V alloys formed via HIP processing using different particle size of metallic powders especially with different diameter distributions of Ti-6Al-4V alloy spherical powders.

This study was performed to investigate the influence of diameter distributions in metallic Ti-6Al-4VELI (extra low interstitial) powders on the microstructures and mechanical properties of HIP Ti-6Al-4VELI specimens. Earlier studies of alloys prepared from various compositions of metallic powders indicated that their microstructures and mechanical properties were closely correlated with their oxygen and other interstitial composition. As a consequence, in this present investigation, we report the microstructural analysis and mechanical characterization of Ti-6Al-4VELI alloy parts fabricated with three diameter distributions of Ti-6Al-4VELI spherical powders by HIP, which were manufactured via plasma rotating electrode processing (PREP).

\section{Experiment}

The morphology of spherical powders and micrograph of cross-section for Ti-6Al-4VELI are shown in Fig. 1. It can be seen that the powder is typical spherical powder, and evenly distributes in Fig.1a.

Three diameter distributions of Ti-6Al-4VELI (Extra Low Interstitial) alloy spherical powders were manufactured via plasma rotating electrode processing (PREP) with the Ti-6Al-4VELI rotating electrode bars, which were placed in the pre-designed stainless steel capsule (diameter: $40 \mathrm{~mm}$; capsule height: $100 \mathrm{~mm}$ ). After the evacuation of capsule, the powders were poured into the vessel via small stainless steel tube with little gas back-flow. Then, the top and bottom of the capsule were sealed via electron-beam welding processing in order to prevent cracking while HIP process. Finally, three capsules with three diameter distributions of powders were pressed at temperatures $940^{\circ} \mathrm{C}$ and pressure $120 \mathrm{MPa}$ when temperature and pressure increase simultaneously during HIP process, as shown in Fig.2. After $3 \mathrm{~h}$ thermal insulation and holding pressure, the capsules were taken out after HIP equipment cooling to normal temperature and pressure as shown in Fig.3, labeled as specimen 1-1, 1-2, 1-3, corresponding to three diameter distributions of powders: fine powders $(45 \sim 100 \mu \mathrm{m})$, medium powders $(100 \sim 150 \mu \mathrm{m})$ and coarse powders $(150 \sim 250 \mu \mathrm{m})$, respectively. The powders were canned and pressed at temperatures of $940{ }^{\circ} \mathrm{C}$ and pressure of $120 \mathrm{MPa}$ when temperature and pressure increase simultaneously during HIP process (see Table 1 and 2).

The relative densities of Ti-6Al-4VELI specimens after HIP process were measured based on Archimedes' principle. The microstructure, metallurgical structure and components of

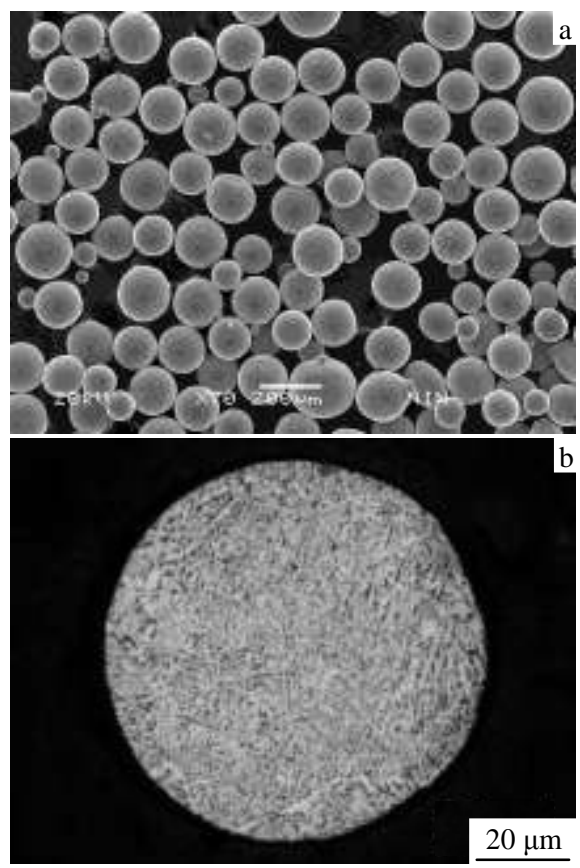

Fig.1 SEM morphology of spherical powders (a) and OM micrograph (b) of cross-section for Ti-6Al-4VELI

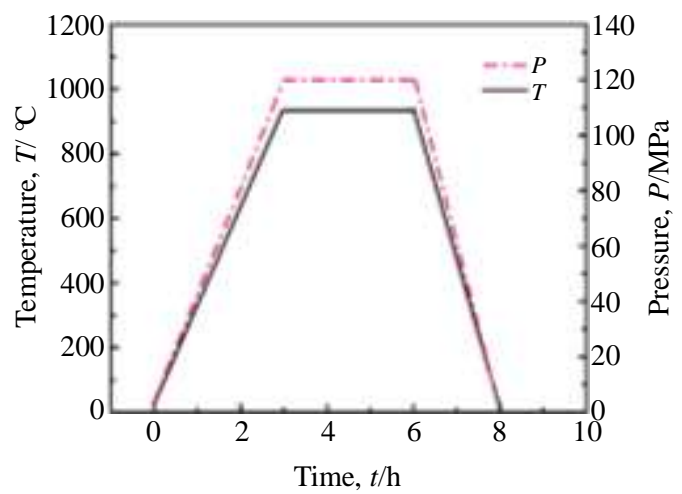

Fig. 2 Process route of Ti-6Al-4VELI specimen with three diameter distributions of metallic powders by HIP

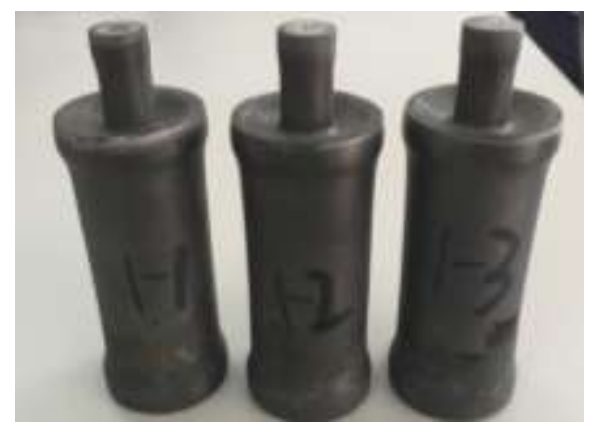

Fig.3 Ti-6Al-4VELI specimens with three diameter distributions of metallic powders 
Table 1 Chemical composition of Ti-6Al-4VELI spherical powders used in this study (wt\%)

\begin{tabular}{|c|c|c|c|c|c|c|c|c|c|}
\hline \multirow{2}{*}{ Standard } & \multirow{2}{*}{ Alloy } & \multicolumn{8}{|c|}{ Actual composition } \\
\hline & & $\mathrm{Al}$ & $\mathrm{V}$ & $\mathrm{Fe}$ & $\mathrm{C}$ & $\mathrm{N}$ & $\mathrm{H}$ & $\mathrm{O}$ & $\mathrm{Ti}$ \\
\hline \multirow{2}{*}{ AMS4998 ${ }^{[17]}$} & Ti-6Al-4VELI & 6.20 & 4.10 & 0.15 & 0.08 & 0.01 & 0.011 & 0.10 & Bal. \\
\hline & Gr5 & $5.50 \sim 6.75$ & $3.50 \sim 4.50$ & 0.30 & 0.10 & 0.04 & 0.012 & $0.13 \sim 0.18$ & Bal. \\
\hline
\end{tabular}

Table 2 Characteristics of the Ti-6Al-4VELI spherical powders used in this study

\begin{tabular}{|c|c|c|c|c|c|c|c|c|}
\hline Specimen & Powders & Diameter/ $\mu \mathrm{m}$ & $D_{10} / \mu \mathrm{m}$ & $D_{50} / \mu \mathrm{m}$ & $D_{90} / \mu \mathrm{m}$ & Packing density $/ \mathrm{g} \cdot \mathrm{cm}^{-3}$ & Tapping density $/ \mathrm{g} \cdot \mathrm{cm}^{-3}$ & Flow ability $(\mathrm{s} / 50 \mathrm{~g})$ \\
\hline $1-1$ & Fine & $45 \sim 100$ & 58.99 & 81.19 & 111.69 & 2.56 & 2.83 & 37.06 \\
\hline $1-2$ & Medium & $100 \sim 150$ & 82.11 & 118.52 & 169.56 & 2.49 & 2.79 & 35.13 \\
\hline $1-3$ & Coarse & $150 \sim 250$ & 127.34 & 175.57 & 241.64 & 2.38 & 2.95 & 33.29 \\
\hline
\end{tabular}

specimens were analyzed through Optical Microscope (OM), Scanning Electron Microscopy (SEM) and Energy Dispersive Spectroscopy (EDS) methods, respectively. The mechanical properties of specimens were also investigated through machining process based on ASTM E $8 \mathrm{M}^{[15,16]}$ at the room temperature. In addition, the microstructures of the fractured surfaces were also examined b scanning electron microscopy (SEM).

\section{Results and Discussion}

\subsection{Relative density of HIPed Ti-6Al-4VELI specimens}

As mentioned in the previous section, the relative densities of specimen 1-1, 1-2, 1-3 are 4.374 .36 and $4.35 \mathrm{~g} / \mathrm{cm}^{3}$ analyzed based on Archimedes' principle, respectively, as shown in Fig.4. Three diameter distributions of HIP Ti-6Al- 4VELI specimens are within $99.99 \mathrm{wt} \%$, equally as the theoretical density of Ti-6Al-4VELI alloy bar, $4.5 \mathrm{~g} / \mathrm{cm}^{3}$. However, there are also several tinny distinctions of density among these specimens, which reveals the fact that relative density of HIP specimen using fine powders (diameter $45 \sim 100 \mu \mathrm{m}$ ) is much closer to the relative density of Ti-6Al-4VELI alloy bars, better than the relative density of HIP specimen 1-2 and 1-3. In addition, the relative density of HIP Ti-6Al-4VELI specimens will increase as the diameter distribution decreases, which indicates fine powders may show better microstructures and mechanical properties.

\subsection{Microstructure of HIPed Ti-6Al-4VELI specimens}

Fig. 5 shows the metallurgical microstructures developed by HIP Ti-6Al-4VELI specimens pressed at temperature of
$940{ }^{\circ} \mathrm{C}$ and pressure of $120 \mathrm{MPa}$ when temperature and pressure increase simultaneously. After $3 \mathrm{~h}$ thermal insulation and holding pressure, according to the comparison of microstructures for each specimen, 1-1, 1-2 and 1-3 present lathlike $\alpha$ and equiaxed $\alpha$ phases with intergranular $\beta$ phases, as shown by arrows in Fig. $5 \mathrm{a}, 5 \mathrm{~b}$ and $5 \mathrm{c}$, respectively. In addition, as the diameter of Ti-6Al-4VELI spherical powders diameter increases from $45 \mu \mathrm{m}$ to $250 \mu \mathrm{m}$, the lathlike $\alpha$ and equiaxed $\alpha$ phases are grown and coarsened obviously. The grain of lathlike $\alpha$ phases turns to be much longer as well as the equiaxed $\alpha$ phases change from the smaller one to bigger one, accompanied by $\beta$ grain boundaries combinations.

According to Zhang et al. ${ }^{[18]}$, a lathlike structure forms in the central region of the particles, while equiaxed $\alpha$ grains are mainly generated at previously existing particle boundaries and at grain boundaries inside the powders. In this case,

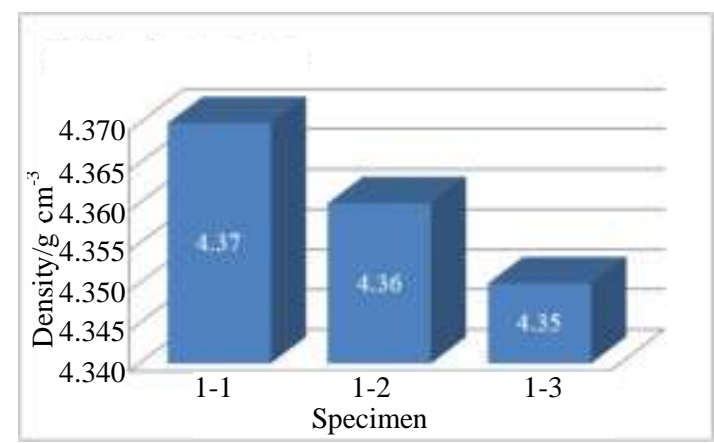

Fig. 4 Density of HIP Ti-6Al-4VELI specimens
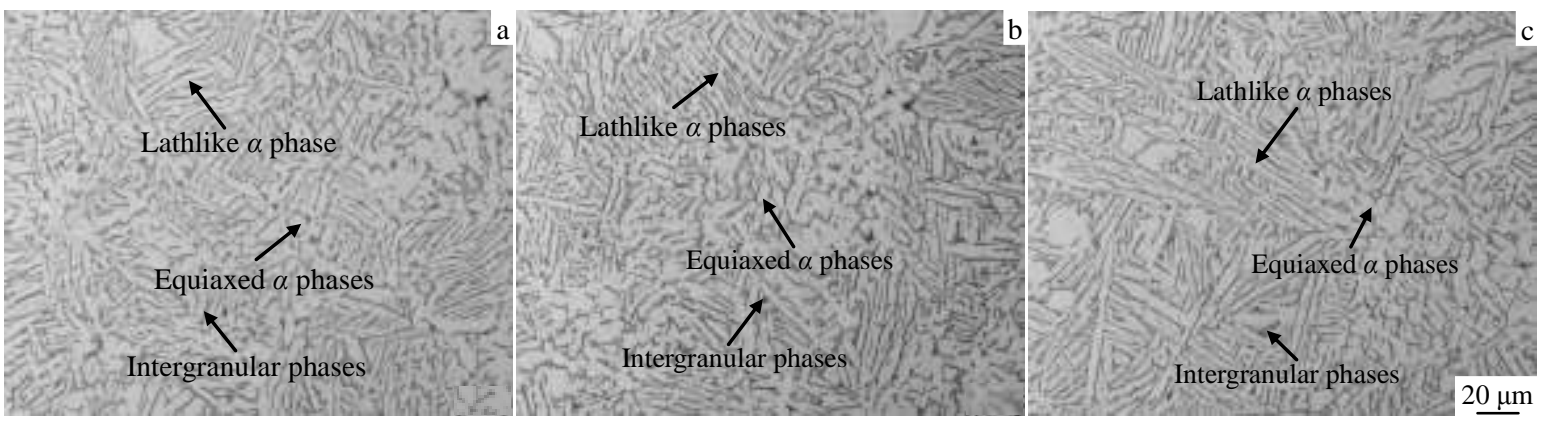

Fig.5 OM micrographs of HIP Ti-6Al-4VELI specimens: (a) 1-1, (b) 1-2, and (c) 1-3 
considerable deformation occurs locally at the boundaries, resulting in recrystallization and the recreation of newly equiaxed $\alpha$ phases in coarse powders. The original microstructures of Ti-6Al-4VELI spherical powders are primary martensite due to rapid cooling during PREP processing (Fig. 1b). The original morphologies transform into lathlike phase at non-boundaries regions and equiaxed $\alpha$ phase at particle boundaries. Thus, the recrystallization and the recreation of newly phases would coarsen with increases in diameter of Ti-6Al-4VELI spherical powders. The reason of changeable lathlike phases and equiaxed $\alpha$ phases can be attributed to the fact that surface tension would increase as the specific surface area rises, as well as the particle size of powder decreases. Thus, as the diameter distributions of Ti-6Al-4VELI spherical powders increase from $45 \sim 100 \mu \mathrm{m}$ to $150 \sim 250 \mu \mathrm{m}$, their specific surface area would decrease due to the surface free energy of grain rising, which also improve the nucleation and growth of smaller gains.

As a result, the fine powders $(45 \sim 100 \mu \mathrm{m})$ used for HIP processing present fine grain appearance corresponding to fine morphologies of lathlike phases and equiaxed $\alpha$ phases as shown in Fig. 5a. However, the medium powders (100 150 $\mu \mathrm{m})$ and coarse powders $(150 \sim 250 \mu \mathrm{m})$ would show medium and coarse grain appearances corresponding to medium and coarse morphologies of lathlike phases and equiaxed $\alpha$ phases as shown in Fig. 5b and 5c. Microstructural characteristics are listed in Table 3.

\subsection{Mechanical properties of HIPed Ti-6Al-4VELI specimen}

Fig. 6 shows the tensile behavior of the HIPed Ti-6Al4VELI specimens at room temperature. As the particle size of Ti-6Al-4VELI spherical powder increases, the yield and tensile stresses of the samples decrease as well as the elongation and reduction of area decrease. For instance, the yield and tensile stresses decline continuously as the diameter distributions of Ti-6Al-4VELI spherical powder increase from $45 \sim 100 \mu \mathrm{m}$ to $150 \sim 250 \mu \mathrm{m}$. Irrespective of their initial microstructures, the yield strength of Ti-6Al- 4VELI specimens decreases from 918 to $895 \mathrm{MPa}$ and the tensile strength of Ti-6Al-4VELI specimens decrease from 1018 to $996 \mathrm{MPa}$. In addition, the elongation of Ti-6Al-4VELI specimens decrease from $18.9 \%$ to $17.6 \%$ and the reduction area of Ti-6Al-4VELI specimens decrease from $48.7 \%$ to $46.5 \%$ (see Table 4 ). In general, aming the HIPed Ti-6Al-4VELI specimens under different diameter distributions of powders testing, specimen 1-1 used for HIP processing exhibits higher yield and tensile stresses than specimen 1-2,1-3, demonstrating the hardening effect resulting from diameter refinement which reveals the mechanical response of the Ti-6Al-4VELI specimens is associated with the different diameter distributions of Ti-6Al4VELI spherical powders. These results are attributed to the change of diameter of powders. When the diameters of Ti-6Al-4VELI spherical powders decrease, the surface free energy of grain in powders will increase. Therefore, the grain
Table 3 Microstructural characteristic of HIPed Ti-6Al-4VELI specimens

\begin{tabular}{ccccc}
\hline Specimen & $d / \mu \mathrm{m}$ & $d_{\alpha} / \mu \mathrm{m}$ & $l_{\alpha} / \mu \mathrm{m}$ & $w_{\alpha} / \mu \mathrm{m}$ \\
\hline $1-1$ & $45 \sim 100$ & $5.57 \pm 1.20$ & $25.07 \pm 5.15$ & $5.21 \pm 0.57$ \\
$1-2$ & $100 \sim 150$ & $6.43 \pm 0.81$ & $37.55 \pm 4.58$ & $4.33 \pm 0.45$ \\
$1-3$ & $150 \sim 250$ & $7.78 \pm 0.36$ & $46.86 \pm 8.75$ & $3.27 \pm 0.50$ \\
\hline
\end{tabular}

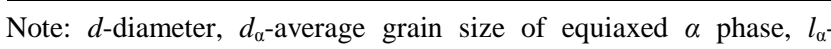
length of lathlike $\alpha$ phase, $w_{\alpha}$-width of lathlike $\alpha$ phase

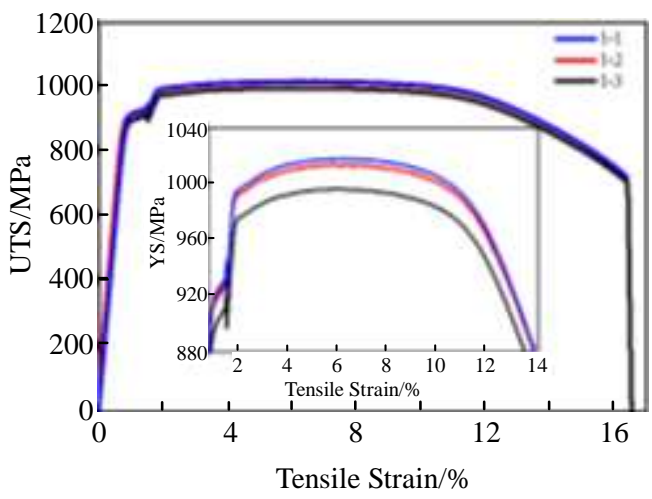

Fig.6 Stress-strain curves of HIPed Ti-6Al-4VELI specimens testing at room temperature

size refinement would happen spontaneously, which affects the mechanical properties of HIP Ti-6Al-4VELI specimens.

Moreover, according to Kanamori et al. ${ }^{[19]}$, most of the voids appeared during $\mathrm{Ti}$ alloys nucleation at the interface between alpha and beta phases, suggesting that increasing interface areas would lead to an increase in the number of voids and prohibition of their growth, which indicates refined microstructures may exhibit higher strength and ductility compared with coarser structures, corresponding to the different particle sizes of Ti-6Al-4VELI spherical powders. In this study, fine powders $(45 \sim 100 \mu \mathrm{m})$ used for HIP processing with more equiaxed morphologies had a larger interface area than specimen 1-2, and 1-3 with more lathlike morphologies. Thus, during deformation, void formations in 1-1 specimen may have become activated resulting in higher strength and ductility than specimen 1-2 and 1-3.

\subsection{Fracture microstructure of HIPed Ti-6Al-4VELI specimen}

Fig.7 exhibit 40 times magnification fractographs of HIPed Ti-6Al-4VELI specimens tested at room temperature. These fractographs present the feature of intergranular fracture which shows cup-and-cone fracture obviously. These morphologies can be divided into two regions: in the central (region A), dimple structures and shear-lip (region B), which is also the typical microstructures of casting fracture. Fig. 7a shows plenty dimples distributing inside the region $\mathrm{A}$ and prominent shear lip of HIP Ti-6Al-4VELI specimens. In addition, the neck cross-sectional area of cup-and-cone fracture is smaller than Fig.7b and Fig.7c, which reveals specimen 1-1 used for 
Table 4 Mechanical properties of HIPed Ti-6Al-4VELI specimens testing at room temperature

\begin{tabular}{cccccc}
\hline Specimen & Diameter/ $\mu \mathrm{m}$ & UTS/MPa & YS/MPa & El/\% & RA/\% \\
\hline $1-1$ & $45 \sim 100$ & 1018 & 918 & 18.9 & 48.7 \\
$1-2$ & $100 \sim 150$ & 1014 & 911 & 18.0 & 47.2 \\
$1-3$ & $150 \sim 250$ & 996 & 895 & 17.6 & 46.5 \\
\hline
\end{tabular}

HIP processing with more dimples inside of region $\mathrm{A}$ has better ductility than specimen 1-2, 1-3.

Fig. 8 shows 500 times magnification fractographs of HIP Ti-6Al-4VELI specimens which illustrates the dependence of the initial microstructure on the fracture features of the specimens tested at room temperature. Specimen 1-1 presents more dimples than specimen 1-2 and 1-3. The dimple size appears to increase with increasing distribution diameter of Ti-6Al-4VELI spherical powders as shown in Fig. 8b and Fig. $8 \mathrm{c}$. As the particle size distributions of specimen 1-1 to 1-3 increase, the dimple size of fracture in specimens increases in the interface of $\alpha$ and $\beta$ phase, where the depth of voids decreases, indicating less ductility. Higher magnification fractographs of HIP Ti-6Al-4VELI specimens are shown in Fig.9. The dimple size increases obviously with increasing distribution of particle size of powders. In this case, smaller and deeper void disappears preferentially with increasing
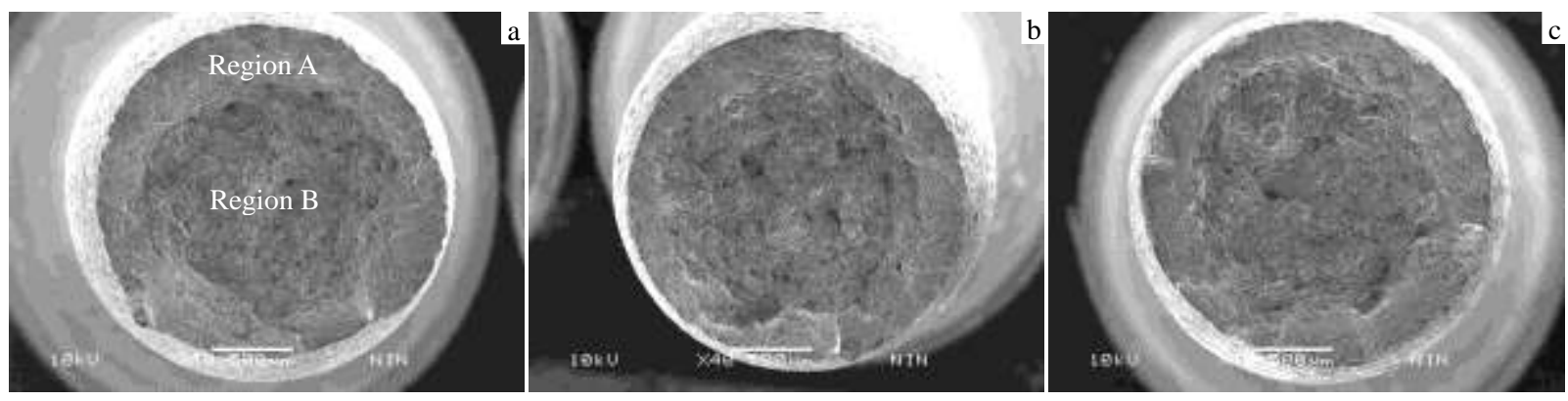

Fig.7 SEM cup-and-cone fracture with a prominent shear lip of HIPed Ti-6Al-4VELI specimens pressed at room temperature: (a) 1-1, (b) 1-2, and (c) 1-3
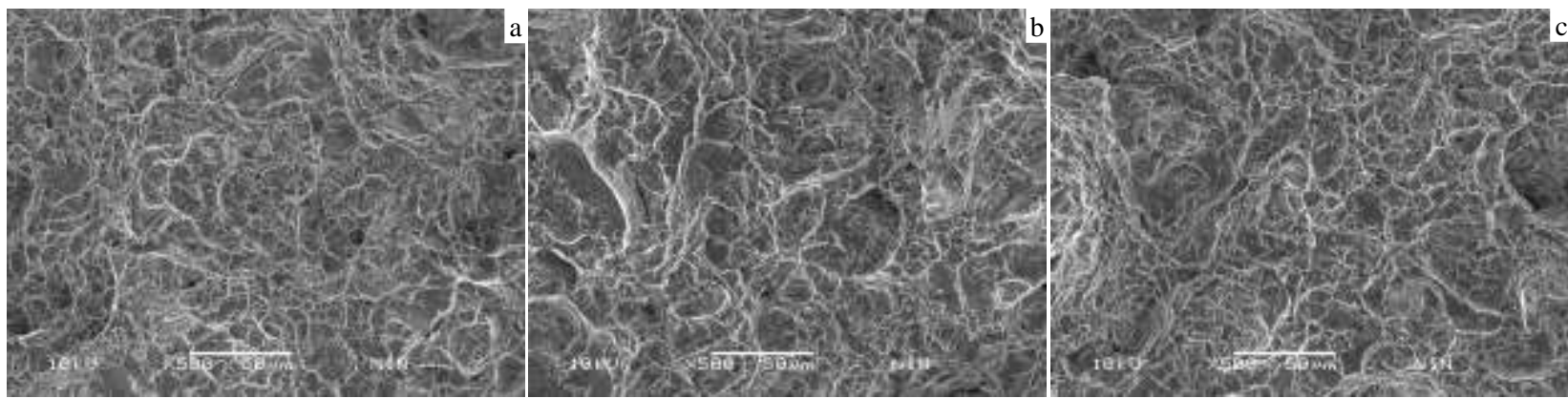

Fig. 8 SEM cup-and-cone fracture with a prominent shear lip of HIPed Ti-6Al-4VELI specimens pressed at room temperature: (a) 1-1, (b) 1-2, and (c) 1-3
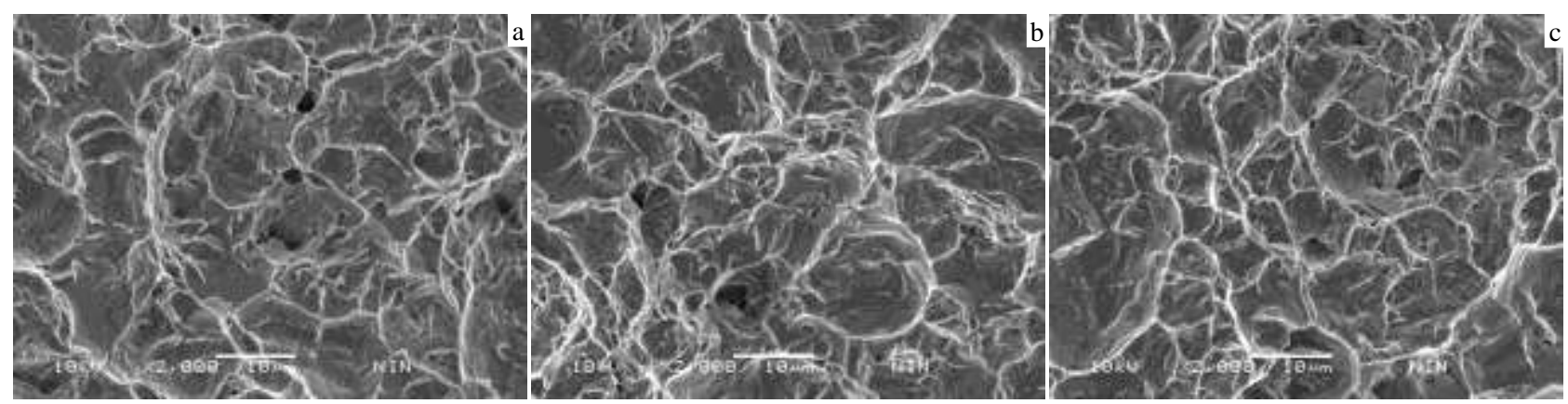

Fig.9 SEM cup-and-cone fracture with a prominent shear lip of HIPed Ti-6Al-4VELI specimens pressed at room temperature: (a) 1-1, (b) 1-2, and (c) 1-3 


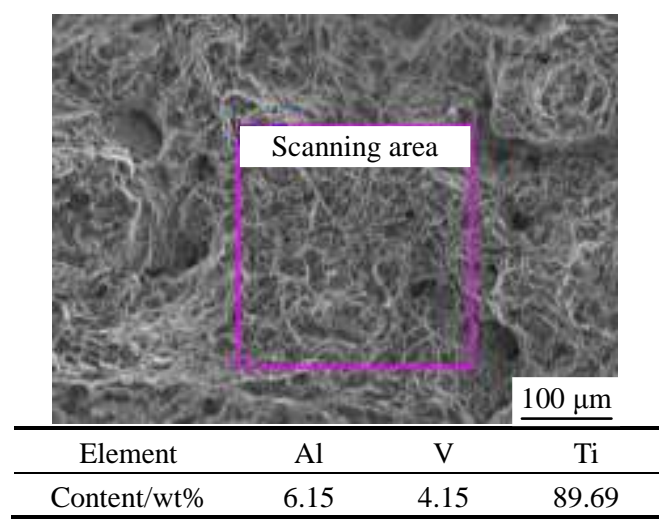

Fig.10 EDS analysis area and result of specimen 1-1 fracture at room temperature

particle size distributions of specimen 1-1 to 1-3. Moreover, Fig.9c shows more platforms shaping from many dimples and seldom transition regions to the fracture, which resulting in a decrease in ductility of Ti-6Al-4VELI specimens. These tendencies are in good agreement with the results of the tensile test as illustrated in Fig.6, corresponding to the observations of the metallographic phase microstructure of the fractured HIP Ti-6Al-4VELI specimens in Fig.5.

\subsection{EDS analysis of fractures in HIPed Ti-6Al-4VELI specimens}

Fig.10 exhibits EDS analysis area and result of specimen 1-1 fracture at room temperature. It is identified that the composition distribution of specimen 1-1 never changes the original composition of Ti-6Al-4VELI electrode bars used for spherical powder producing. The element content is controlled in the range of the Ti-6Al-4V nominal composition which indicates HIP processing of Ti-6Al-4VELI spherical powders used for HIP would not change the chemical composition of the specimens. These results are attributed to the physical processing of HIP. The spherical powders were canned and pressed under certain temperature and pressure meaning HIP process subjects a component to both elevated temperature and isostatic gas pressure in a high pressure containment vessel. The pressurizing is most widely used is argon. An inert gas is used, so that the material does not chemically react, which represent the physical change and would not change the composition of powders.

\section{Conclusions}

1) The relative density of Ti-6Al-4VELI specimen made from fine powders is much closer to the theoretical density of Ti-6Al-4VELI alloys, which shows better relative density than that made from medium and coarse powders.

2) Equiaxed structures and lamellar phase morphologies are exhibited and they are strongly associated with the diameter distributions of spherical powders. Fine powders used for HIP processing present smaller equiaxed $\alpha$ and lamellar phase. However, medium and coarse powders show bigger equiaxed $\alpha$ and lamellar phase, which could attribute to the different surface tension of spherical powders.

3) The yield and tensile strength as well as the elongation and the reduction area of specimens decline with increasing the diameter distribution of spherical powders, from $45 \sim 100 \mu \mathrm{m}$ to $150 \sim 250 \mu \mathrm{m}$, demonstrating the hardening effect resulting from grain size refinement, which reveals the mechanical response of specimens associated with the different diameter distributions of spherical powders.

4) Ti-6Al-4VELI specimens show ductile cup-and-cone fractures with a prominent shear lip. The size of typical dimple structures increases obviously with increasing diameter of powders. Moreover, the fracture mechanism is associated with more platforms shaping from many dimples and seldom transition regions to the fracture, resulting in a decrease in ductility of specimens. These tendencies are confirmed by the results of the tensile test and observations of morphologies. Meanwhile, EDS analysis result of fractures demonstrates HIP processing of spherical powders would not change the chemical composition of specimens.

\section{References}

1 Kim Y, Kim E P, Song Y B et al. J Alloy Compd[J], 2014, 603: 207

2 Froes F H. Adv Mat Proc[J], 2012(9): 16

3 Jovanovic M T, Tadic S, Zec S. Materials and Design[J], 2006, 27: 192

4 Peters M, Hemptenmacher J, Kumpfert J et al. In: Leyens C, Peters $\mathrm{M}$ eds. Titanium and Titanium Alloys-Fundamentals and Applications[C]. Wiely-VCH, Weinheim, 2003: 1

5 Xu L, Guo R, Bai C et al. J Mater Sci Technol[J], 2014, 30: 1289

6 Qian M, Froes F H eds. Titanium Powder Metallurgy: Science, Technology and Applications $[\mathrm{C}]$. Oxford, UK: ButterworthHeinemann Ltd, 2015: 33

7 Qian M, Froes F H eds. Science, Technology and Applications[C]. Oxford, UK: Butterworth-Heinemann Ltd, (2015: 51

8 Zhang D, Raynova S, Nadakuduru V et al. Mater Sci Forum[J], 2009, 618-619: 513

9 Wang L, Lang Z, Shi H. Trans Nonferr Met Soc China[J], 2007, 17: 639

10 Guo Z, Malinov S, Sha W. Comput Mat Sci[J], 2005, 32: 1

11 Teraoku T. Int J Powder Met[J], 2008, 44: 57

12 Dunkley J. In: Chang I, Zhao Y eds. Advances in Powder Metallurgy[C]. Woodhead Publishing, 2013: 3

13 German R M. Materials[J], 2013(6): 3641

14 Horke K, Ruderer B, Singer R. Powder Metall[J], 2014, 57: 283

15 Kim Y, Song Y B, Lee S H. J Alloy Compd[J], 2015, 637: 234

16 Mc Cracken C G, Barbis D P, Deeter R C. Powder Metall[J], 
2011, 54: 180

17 AMS4998[S]. 2013

18

Zhang K, Mei J, Wain N et al. Metall Mater Trans A[J], 2010,

49A: 1033

19 Kanamori S, Abe E, Tagawa T et al. Proc 10th Int Conf Fracture [C]. Honolulu, USA, 2001

\title{
三种不同粒径分布的 Ti-6AI-4VELI 球形粉末热等静压件的显微组织及力学性能
}

\author{
曾 光 ${ }^{1,3}$, 毛小南 ${ }^{1}$, 赵永庆 ${ }^{1}$, 黄朝文 ${ }^{1}$, 梁书锦 ${ }^{2}$, 韩志宇 ${ }^{2}$, 间 $飞^{2}$, 张平祥 ${ }^{1,2}$ \\ (1. 西北有色金属研究院, 陕西 西安 710016) \\ (2. 西安欧中材料科技有限公司, 陕西 西安 710018)
}

(3. 皇家墨尔本理工大学, 澳大利亚 维多利亚州 墨尔本 3001)

\begin{abstract}
摘 要: 对经等离子旋转电极法制备的 3 种不同粒径分布的 Ti-6Al-4VELI (低间隙) 合金球形粉末，经热等静压(HIP)工艺制成的制件显 微组织和力学性能进行了研究。Ti-6Al-4VELI 合金球形粉末热等静压制件工艺为 $940{ }^{\circ} \mathrm{C} / 120 \mathrm{MPa}$ 同时升温升压。利用光学显微镜 (OM), 扫描电子显微镜 (SEM) 及能谱仪 (EDS) 研究 HIP 制件中的 $\alpha+\beta$ 混合相。结果表明, HIP 制件的显微组织与粉末粒径分布有关。与

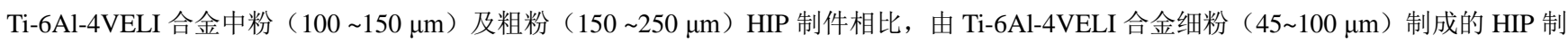
件呈现出更为优异的显微组织及力学性能, 表现为更为细化的显微组织和更高的抗拉强度及延伸率, 这与粉末 HIP 制件的断口分析结果 相一致。
\end{abstract}

关键词：Ti-6Al-4VELI 合金球形粉末；HIP；粒径分布；显微组织；力学性能

作者简介: 曾 光, 女, 1983 年生, 硕士, 高级工程师, 西北有色金属研究院钛合金研究所, 陕西 西安 710016, 电话: 029-86231095, E-mail: guangbright@126.com 